Карамхудоев Ш.Х. Цель и смысл существования человека с точки зрения Носира Хусрава и Джалаледдина Руми

УДК 124.5

DOI: $10.21779 / 2500-1930-2017-32-3-150-156$

\title{
HI.X. Карамхудоев
}

\section{Цель и смысл существования человека с точки зрения Носира Хусрава и Джалаледдина Руми}

Таджикский государственный институт языков им. Сотима Улугзода; Таджикистан, 734019, г. Душанбе, ул. Мухамадиев 17/6; shukratk@mail.ru

В статье представлен сопоставительный методом анализ проблемы человека в учениях Носира Хусрава и Джалаледдина Руми. Обосновывается идея о том, что согласно воззрению названных мыслителей, каждое из троичного порождения (минерал, растение, животное) эволюционным путём растворяется в сушестве выше себя и таким образом поднимается до степени человека. Человек в свою очередь в результате борьбы с самим собой достигает степени ангела.

Отмечается, что каждое из троичного порождения постепенно проявляет большее превосходство над другими, так как владеет большим знанием. Делается вывод о том, что превосходство человека над другими заключается в его уровне знания.

Ключевые слова: знания, человек, минерал, акция, потенциия, растение, животное, ангел.

Мир и всё, что в нём существует, сотворены ради человека, то есть человек в иерархии бытия является последним звеном. Такую позицию по отношению к человеку занимают большинство философов мира.

Сходные воззрения характерны и для философий Носира Хусрава и Джалаледдина Руми. По их мнению, смысл каждого из троичного порождения (минерал, растение, животное) возникшего до появления человека, заключается в том, чтобы посредством их последний стал совершенным. Таким образом, согласно мнению Носира Хусрава и Джалаледдина Руми, вся божественная тайна скрыта в человеке. По убеждению Носира Хусрава, цель сотворения каждого существа зависит от его окончательного результата. Мудрецы истинной религии и философы по той проблеме, согласно которой начальной причиной следствия является его конечная причина, занимают одинаковую позицию. Следовательно, то, что возникает последней у созданного, является его первопричиной. Поэтому мудрецы говорили: «Начало замысла в действии будет последним». Началом замысла плотника является то, что королю нужен трон, а его последняя работа - то, чтобы король сидел на троне. И причиной появления мира является человек, после него ничего не появилось. Целью создателя мира в начале этого созидания было появление человека, и из его творения в конце появился человек [12, с. 23].

Мир, с точки зрения мыслителя, является причиной, а человек следствием, следовательно, причина всегда предшествует следствию, так как «один» предшествует числу или «частица» предшествует целому [10, с.78].

С точки зрения Носира Хусрава, нужда Всеобщей души стала причиной появления мира. А человек как основная и конечная цель Всеобщей души считается пределом творения. Нужда Всеобщей души, по мнению названного мыслителя, считается её недостатком. Для того чтобы Всеобщая душа исправила этот недостаток и стала совершенной, нужно время. Следовательно, время появилось от действия Всеобщей души, 
Карамхудоев Ш.Х. Цель и смысл существования человека с точки зрения Носира Хусрава и Джалаледдина Руми

чтобы она в его пределах достигла степени совершенства. Достичь совершенства и степени Всеобщего разума ей помогает «предел существа мира» - человек. То есть, по убеждению Носира Хусрава, каждый человек должен знанием, религией и воздержанием очищать свою разумную душу от аморального явления, чтобы этим способствовать совершенствованию Всеобщей души, так как разумная душа человека является частью Всеобщей души [12, с. 28]. Чем ближе человек к Всеобщему разуму, тем более он становится совершенным, и это способствует совершенствованию Мировой души. Аналогичного мнения придерживается в своем учении его единоверец Ал-Кирмани [15, с. 206]. Носир Хусрав и Джалаледдин Руми едины в мнениии, что человек в мироздании является последним существом и всё в мире создано ради него. Носир Хусрав в книге «Хон-ул-ихвон» («Трапеза братьев») данную идею излагает следующим образом: «Как в рождении растительного существа сначала появляются ветви, листва и шипы, которые являются не изящными, а напоследок в нём появляются плоды, которые являются ценными, и плоды дерева господствуют над ветвями и листьями, так как вся польза от дерева приходит к плоду. Прочность и достоинство дерева за его плодами» [12, с.120].

Руми данную идею излагает так:

Внешне та ветка - корень плода,

По внутреннему [смыслу] она появилась ради плода

Если бы не желание и надежда [собрать] плоды,

Разве стал бы садовник сажать корень дерева?

Значит, по сути, то дерево родилось из плода,

Даже если формально он был порождением дерева.

Начальный замысел исполнен последним,

Особенно замысел, который является описанием Предвечности [3, с. 63-64].

Из вышеприведенных примеров становится ясно, что мнения Носира Хусрава и Джалаледдина Руми сходны не только по содержанию, но и по форме.

Российский учёный А.В. Смирнов, анализируя учение Ибн Араби о человеке, приходит к такому выводу: «Здесь человек предстает перед нами уже не только как непременное условие существования мира («охраняющая печать»), но и как цель его создания (лишь ради него Бог ниспосылает «милость», т. е. бытие своему Творению)» $[14$, c. 73]. Высказывание Смирнова А.В. можно в полной мере отнести и к учениям Носира Хусрава и Джалаледдина Руми, так как они тоже убеждены в том, что целью творения является только человек.

Хотя мир и создан ради человека, но цель заключается не в сотворении его телесной формы, а в достижении духовного совершенствования [8, с. 153], ибо тело человека в числе других материальных веществ остаётся в этом мире. А человеческая душа, будучи смыслом и целью сотворения, соединяется со своей основой и продолжает жить. Так как смысл мироздания заключен в совершенствовании разумной души, то для усовершенствования благородного духа избрано наилучшее тело, и последнее тоже нуждается в воспитании и уходе. То есть человек, как в духовном, так и в телесном отношении превосходит все существа мира. Как отмечалось выше, согласно мнению Носира Хусрава и Джалаледдина Руми, то, что в творении является последним, то и является смыслом и значением творения. Таким образом, человек как биологическое существо в цепи созидания мира является последним звеном, и последней у него появляется разумная душа. С точки зрения Носира Хусрава, мир создан ради человека, а человек ради разумной души, а разумная душа - ради Всеобщей души. Руми также придержи- 
Карамхудоев Ш.Х. Цель и смысл существования человека с точки зрения Носира Хусрава и Джалаледдина Руми

вается этот мнения, но только начало его цепи творения начинается с Любви, а вместо разумной души он использует сердце.

Взгляды Носира Хусрава на данную проблему можно представить в виде следующей схемы: мир $\rightarrow$ человек $\rightarrow$ разумная душа $\rightarrow$ Всеобщая душа.

То есть, по мнению Носира Хусрава, Всеобщая душа создала разумную душу ради своего блага. Разумная душа является частью Всеобщей души, и чем больше первая достигает степени совершенства, тем больше последняя приближается к своей цели.

Мнение Руми по вышеназванной проблеме можно представить такой схемой: мир $\rightarrow$ человек $\rightarrow$ сердце $\rightarrow$ Любовь.

Особого различия между взглядами названных философов по данному вопросу не наблюдается, так как сердце всегда уподобляется разумной душе. Сам Носир Хусрав об этом пишет: «Под понятием сердце не понимается кусок мяса, а понимается та разумная душа, которая связана с человеческим сердцем» [12, с. 204]. А Любовь - это действия Всеобщей души, так как всё, что она делает, делает с любовью. То есть каждое существо, стремящееся к совершенству, свидетельствует о наличии любви. Движение, с точки зрения Руми, свойственно Любви, из-за Любови все существа находятся в движении. Носир Хусрав считает движение свойством Всеобщей души. А двигается она из-за любви к своему Создателю. Можно отметить, что свойства, которые Носир Хусрав приписывает Всеобщей душе, Руми приписывает Любви.

Сначала у человека появляется растительная душа, и он начинает, как растение, действовать и развиваться. После этого у него появляется животная душа, и он, как животное, начинает чувствовать голод, у него проявляется потребность в пище. А самой последней у человека появляется разумная душа, являясь не только целью и смыслом человеческой жизни, но и смыслом сотворения Макрокосма.

Итак, если сотворение этого сложного и загадочного Космоса осуществляется ради человека, то тогда возникнут вопросы: а ради чего сотворён человек? Какие тайны человек скрывает в себе? Как может человек постигать тайны своего существования? В чём заключается цель сотворения человека? Каждый мыслитель в разные времена истории относительно этой проблемы имеет свою точку зрения. Например, в русской религиозной философии на человечество, его цели и смысл существования смотрят через призму личности Христа [2, с.76]. В современной философии не существует единого и однозначного ответа на поставленные нами вопросы, хотя и существует тенденция дальнейшего изучения развития человеческой природы технологическими средствами $[16$, c. 66].

По мнению Носира Хусрава, человеческое тело создано ради её разумной души, а по мнению Руми - ради сердца, что является одним и тем же. Превосходство человека заключается в его разумной душе, а всё, что в иерархии бытия появилось до человека, по достоинству является ниже него и старается постепенно приблизиться к нему. Таким образом, каждое низшее существо растворяется в существе выше себя. Носир Хусрав по этому поводу пишет: «...повиновение последнего претерпевающего, который есть земля, последнему действующему, заключенному в семени растения, обусловлено принятием им формы последнего действующего и пребыванием в ней. Другие, более высшие, чем земля, стихии, обладающие некоторой долей действия, помогают этому растительному действующему и покоряют себе того последнего претерпевающего. Таково состояние повиновения растения животному, ибо когда растение принимает форму животного, покоряется ему, его действие завершается и переходит в действие животного. Поскольку этот порядок познан, постольку скажем, что повиновение человека Создателю мира должно происходить в соответствии с особенностями его действия. У человека 
Карамхудоев Ш.Х. Цель и смысл существования человека с точки зрения Носира Хусрава и Джалаледдина Руми

есть две силы, благодаря которым он отличается от других животных. Одна из них знание, другая - действия по этим знаниям. Следовательно, человек должен повиноваться своему Создателю сообразно знаниям и деяниям, дабы приобрести форму своего Создателя. Когда человек отделяется от своего тела, его действие уподобляется действию Создателя мира. Точно так же, когда растительная душа оставила своё тело, ее действие перешло в действие животного» [11, с. 241-242]. сравом:

Руми тоже по данной проблеме занимает аналогичную позицию с Носиром Ху-

Умер я как минерал и стал растительным,

Как растительный я погиб и стал животным.

От состояния животного я умер и стал человеком,

Тогда зачем мне бояться? Когда я стал меньше от смерти?

Ещё мне одного старания, и погибну от человеческого состояния,

Чтобы завоевать степень ангела.

От состояния ангела надо мне идти дальше,

«Всякая вещь гибнет, кроме Его лика».

Ещё раз мне надо пожертвовать ангельского состояния,

И то, что не влезет в воображение стану таким...

Когда вода из кувшина льется в речку

Уничтожается и станет речкой (букв. перевод) [4, с. 139].

Из вышеприведённых примеров становится очевидным, что, согласно мнению Носира Хусрава и Джалаледдина Руми, процесс совершенствования человека происходит в соответствии с диалектическим законом отрицания отрицания. Такое диалектическое и эволюционное понимание жизни, с одной стороны, показывает, что жизнь находится в процессе постоянного развития. С другой стороны, указывает на превосходство человека над другими существами, что все повинуются и растворяются в человеке, а он движется дальше до бесконечности. Так как этот процесс, начинаясь с «минерального состояния〉 переходит в растительное, затем в животное и человеческое, заканчивается уровнем ангела и даже выше него [7, с. 148]. То есть один процесс отрицает другой и занимает его место. Неживой минерал жертвуется растению, и больше от этого минерала ничего не остаётся, одушевляется он в растении. А растение в свою очередь жертвует себя животному, его жизнь присоединяется к животному, и больше от этого растения ничего не останется. Жизнь животного жертвуется человеку, и первое начинает жить в человеке. По мнению названных мыслителей, каждое низшее существо поклоняется высшему и исчезает в его бытии. Имея это в виду, Носир Хусрав пишет:

Всякое существо идёт к совершенству,

В потенции каждый несовершенный является совершенным [10, с. 118].

Это последовательное самопожертвование, начиная с телесного заканчивая духовным состоянием, и человек в этом процессе, с точки зрения вышеупомянутых мыслителей, достигает степени ангела. Таким образом, человек тоже покоряется своему Создателю и исчезает в Его бытии. Необходимо отметить, что ангел, по убеждению названных философов, не является объективным бытием, существующим отдельно от человека, а является им же достигнутым степенью и качеством, завоеванными с трудом: минерал $\rightarrow$ растение $\rightarrow$ животное $\rightarrow$ человек $\rightarrow$ ангел.

Смысл жизни человека тоже заключается в этом. Человек должен стремиться к достижению данной цели и постоянно находиться в борьбе с самим собой. Без такого усилия человек не достигнет совершенства. 
Карамхудоев Ш.Х. Цель и смысл существования человека с точки зрения Носира Хусрава и Джалаледдина Руми

Согласно мнению обоих философов, достоинство и превосходство между троичным порождением (минерал, растение, животное) и человеком заключается в степени знания, которым они владеют. То есть постепенно каждое существо владеет большим знанием относительно другого существа. Существо, которое не обладает или недостаточно обладает знанием, жертвует себя существу, имеющему больше знаний, и начинает жить в нём, при этом забывая о собственном существовании. Поэтому человек почитает растение больше, чем минерал, а животное - больше, чем растение. То есть благодаря тому уровню знания, которого достигло животное, оно господствует над растением и является ближе к человеку. Знание, которым обладает человек, больше, чем знание, которым обладает животное. Следовательно, благодаря своему знанию человек приобрел своё достоинство. Поэтому в сравнении с другими существами он ближе всех к Творцу [5, с. 331]. Об этом Носир Хусрав пишет следующее: «Достоинство растения над минералом заключается в том, что растение может брать выгоду от минерала и поэтому является живым. А минерал, не обладая знанием, остаётся мертвым. Та степень знания, которым обладает растение, стало ценным для человека, потому что знание приближает растение к человеку. Животное обладает знанием больше растения, так как оно знает своего врага и оберегает себя от жары и холода». Поэтому над растением, знание которого меньше знания животного, последнее господствует. Человек в приёме пищи приблизил животное к себе, потому что животное со своим знанием ближе к человеку. Человек имеет превосходство и господство над животным, так как он обладает большим знанием. Поэтому с помощью этой силы, находящейся в его разумной душе, он знает скрытый смысл. А животное не обладает таким знанием [9, с. 43-44].

Руми тоже считает, что владение знанием определяет превосходство человеческой души над другими существами. Душа, обладающая знанием больше других, является более совершенной:

Душа не является кроме извещения в испытании,

Кто владеет много информацией, у того и душа больше.

Наша душа значимая, чем животная душа,

Почему? Потому, что у нее информации больше...

Когда душа возрастает, переходит предела,

И душа других вещей повинуется ей (букв. перевод) [4, с. 234].

Такое рациональное обсуждение темы повышает статус знания и науки в обществе. Лишь владение знанием приближает человека к Творцу. У кого знаний больше, тот и ближе к Богу. А когда человек приближается к Богу, он становится могущественным и признаёт своё превосходство над другими созданиями. «Это означает, что человек перестаёт выступать в качестве «раба Божьего», покорного исполнителя божественной воли, но предстаёт свободным соучастником божественного творчества» [2, c. 68].

Могущество человека, с точки зрения Носира Хусрава и Джалаледдина Руми, не имеет предела. Однако человек, не осознавая этого, остается между животным и ангелом. Он не использует своей способности и занимается другими делами, которые станут преградой для достижения совершенства. Поэтому в процессе совершенствования человек отходит от собственного «Я» и становится проявлением божественного «Я» $[13$, с. 332].

Однако немецкий философ И. Кант считает, что «из всех существ человек меньше всего достигает цели своего существования, потому что он тратит свои превосходные способности на такие цели, которых остальные существа достигают с гораздо меньшими способностями и, тем не менее, гораздо надёжнее и проще» [6, с. 24]. 
Карамхудоев Ш.Х. Цель и смысл существования человека с точки зрения Носира Хусрава и Джалаледдина Руми

Задача, которую Носир Хусрав и Джалаледдин Руми поставили перед собой, заключается в том, чтобы напомнить человеку о его достоинстве и превосходстве над другими существами. А достижение данной цели и выполнение своего предназначения возможны только овладев знанием и моралью. Проанализировав учения Носира Хусрава и Джалаледдина Руми о человеке авторы приходят к выводу, что всё бытие пронизано одной мыслью - сердцевиной бытия является человек, который проходит все уровни бытия, и достигает степени выше ангела.

\section{Литература}

1. Бондарева Я.В., Фурсова В.Э. Идея синергии как основа антропологии целостности // Вестник Московского государственного областного университета. Сер.: Философские науки. - 2015. - № 2. - С. 63-69.

2. Бондарева Я.В. Антропологические основы русской религиозной философии // Вестник Московского государственного областного университета. Сер.: Философские науки. - 2017. - № 1. - С. 75-82. DOI: 10.18384/2310-7227-2017-1-75-82.

3. Джалал ад-дин Мухаммад Руми. Маснави-йи Ма'нави (Поэма о скрытом смысле). Четвертый дафтар. - СПб.: Петербургское востоковедение, 2010.

4. Джалолуддин Балхи. Маснавии ма'нави. - Тегеран, 2001. -728 с.

5. Диноршоев Мусо. Трактат Насир-и Хусрава За̄д ал-муса̄фирин // Ишрак: ежегодник исламской философии. - 2013. - № 4.

6. Кант Иммануил. Всеобщая естественная история и теория неба // Мир философии. Ч. II. - М., 1991. - 672 с.

7. Карамхудоев Ш.Х. Идея эволюции троичного порождения и человека в учениях Носира Хусрава и Джалаледдина Руми // Вестник Таджикского национального университета (научный журнал). - 2017. - № 3/1. - С. 147-149.

8. Карамхудоев Ш.Х. Проблема несовместимости свободной воли и религиозного шариата в учении Носира Хусрава и Джалолуддина Руми // Вестник Таджикского национального университета (научный журнал). - 2017. - № 3/2. - С. 152-154.

9. Носир Хусрав. Ваджхи дин (Лик веры). - Душанбе, 2002. - 382 с.

10. Носир Хусрав. Диван стихов. - Тегеран, 2006. - 542 с.

11. Носир Хусрав. Зад ал-мусафирин (Припасы путников). Душанбе, 2005. - 635 с.

12. Носир Хусрав. Куллиёт (Сборник произведений). Т. 3. - Душанбе. 2003. - 353 с.

13. Орхан Мир-Касимов. Некоторые аспекты парадокса подобия божественного и человеческого в истории мусульманской религиозной мысли // Ишрак: ежегодник исламской философии. - 2012. - № 3 .

14. Смирнов А.В. Великий шейх суфизма. - М., 1993. -328 с.

15. Смирнов A.B. Основные черты философского учения Хамид ад-дина алКирма̄ни // Ишрак: ежегодник исламской философии. - 2013. - № 4.

16. Хрисанов В.А., Долин В.A. Образы совершенного человека в современной философии // Вестник Московского государственного областного университета. Сер.: Философские науки. - 2015. - № 4. С. 65-73.

Поступила в редакциию 8 сентября 2017 г. 
Карамхудоев Ш.Х. Цель и смысл существования человека с точки зрения Носира Хусрава и Джалаледдина Руми

UDC 124.5

DOI: $10.21779 / 2500-1930-2017-32-3-150-156$

\section{The purpose of man's existence from the viewpoint of Nosir Husrava and Jalaleddin by} Rumi

\section{Sh.Kh. Karamkhudoev}

Tajik State Institute of Languages named after Sotim Ulugzoda; Tadzikistan, 734019, Dushanbee, Mukhamadiev Str.17/6; shukratk@mail.ru

In this article, a comparative analysis of the problem of man in the teachings of Nosir Khusraw and Jalaleddin Rumi is considered. The idea that according to the opinion of the named thinkers, each of the ternary generation (a mineral, a plant, an animal) is evolutionarily dissolves in the being above itself, and thus rises to the degree of a person. Man, in turn, as a result of the struggle with himself, reaches the degree of an angel.

It is noted that each of the ternary generation gradually manifests a greater superiority over others, since it owns a great deal of knowledge. It is concluded that the superiority of man over others lies in his level of knowledge.

Keywords: knowledge, man, mineral, share, potency, plant, animal, angel.

Received 8 September, 2017 